\title{
Oxygen Scavengers: An Approach on Food Preservation
}

\author{
Renato Souza Cruz, Geany Peruch Camilloto and Ana Clarissa dos Santos Pires
}

Additional information is available at the end of the chapter

http://dx.doi.org/10.5772/48453

\section{Introduction}

Many foods are very sensitive for oxygen, which is responsible for the deterioration of many products either directly or indirectly. In fact, in many cases food deterioration is caused by oxidation reactions or by the presence of spoilage aerobic microorganisms. Therefore, in order to preserve these products, oxygen is often excluded.

Oxygen $\left(\mathrm{O}_{2}\right)$ presence in food packages is mainly due to failures in the packaging process, such as mixture of gases containing oxygen residues, or inefficient vacuum. Vacuum packaging has been widely used to eliminate oxygen in the package prior to sealing. However, the oxygen that permeates from the outside environment into the package through the packaging material cannot be removed by this method (Byun et al., 2011).

Modified atmosphere packaging (MAP) is often used as an alternative to reduce the $\mathrm{O}_{2}$ inside food packaging. However, for many foods, the levels of residual oxygen that can be achieved by regular (MAP) technologies are too high for maintaining the desired quality and for achieving the sought shelf-life (Damaj et al., 2009). The use of oxygen scavenging packaging materials means that oxygen dissolved in the food, or present initially in the headspace, can potentially be reduced to levels much lower than those achievable by modified atmosphere packaging (Zerdin et al., 2003).

In this context, research and developments in the food packaging area have been conducted, aiming to eliminate residual $\mathrm{O}_{2}$. One of the most attractive subjects is the active packaging concept. Active packaging includes oxygen and ethylene scavengers, carbon dioxide scavengers and emitters, humidity controllers, flavor emitters or absorbers and films incorporated with antimicrobial and antioxidant agents (Santiago-Silva et al., 2009).

The most used active packaging technologies for food are those developed to scavenge oxygen and were first commercialized in the late 1970s by Japan's Mitsubishi Gas Chemical 
Company $\left(\right.$ Ageless $\left.^{\circledR}\right)$. In the case of gas scavengers, reactive compounds are either contained in individual sachets or stickers associated to the packaging material or directly incorporated into the packaging material (Charles et al., 2006).

The first patent of an absorber was given in 1938 in Finland. This patent was developed to remove the residual oxygen in headspace of metallic packaging. The method of introduction of hydrogen gas in the packaging to react with oxygen in palladium presence was commercialized in 1960s however this method has never been popularized and well accepted because the hydrogen was unstable during manipulation and storage and, furthermore, it is expensive and unwholesome (Abe and Kondoh, 1989). Recently, more than 400 patents were recorded, mainly in EUA, Japan and Europe, due the great interest by absorbers use (Cruz et al., 2005).

Oxygen scavengers are becoming increasingly attractive to food manufacturers and retailers and the growth outlook for the global market is bullish. Pira International Ltd estimated the global oxygen scavenger market to be 12 billion units in Japan, 500 million in the USA and 300 million in Western Europe in 2001. This market was forecast to grow to 14.4 billion in Japan, 4.5 billion in the USA and 5.7 billion in Western Europe in 2007 (Anon., 2004). In addition, Pira International Ltd. estimated the global value of this market in 2005 to be worth $\$ 588$ million and has forecast this market to be worth $\$ 924$ million in 2010. The increasing popularity of oxygen scavenging polyethylene terephthalate (PET) bottles, bottle caps and crowns for beers and other beverages has greatly contributed to this impressive growth (Anon., 2005).

Overall, oxygen absorbing technology is based on oxidation or combination of one of the following components: iron powder, ascorbic acid, photosensitive polymers, enzymes, etc. These compounds are able to reduce the levels of oxygen to below $0.01 \%$, which is lower than the levels typically found (0.3-3\%) in the conventional systems of modified atmosphere, vacuum or substitution of internal atmosphere for inert gas (Cruz et al., 2007). A summary of the most important trademarks of oxygen scavenger systems and their manufacturers is shown in Table 1.

An appropriate oxygen scavenger is chosen depending on the $\mathrm{O}_{2}$-level in the headspace, how much oxygen is trapped in the food initially and the amount of oxygen that will be transported from the surrounding air into the package during storage. The nature of the food (e.g. size, shape, weight), water activity and desired shelf-life are also important factors influencing the choice of oxygen absorbents (Vermeiren et al., 2003).

Oxygen scavengers must satisfy several requirements such as to be harmless to the human body, to absorb oxygen at an appropriate rate, to not produce toxic substances or unfavorable gas or odor, to be compact in size and are expected to show a constant quality and performance, to absorb a large amount of oxygen and to be economically priced (Nakamura and Hoshino, 1983; Abe, 1994; Rooney, 1995).

The most well known oxygen scavengers take the form of small sachets containing various iron based powders containing an assortment of catalysts. However, non-metallic oxygen 
scavengers have also been developed to alleviate the potential for metallic taints being imparted to food products and the detection of metal by in-line detectors. Non-metallic scavengers include those that use organic reducing agents such as ascorbic acid, ascorbate salts or catechol. They also include enzymatic oxygen scavenger systems using either glucose oxidase or ethanol oxidase (Day, 2003).

\begin{tabular}{|c|c|c|c|}
\hline Company & Trade Name & Type & $\begin{array}{l}\text { Principle/Active } \\
\text { substances }\end{array}$ \\
\hline $\begin{array}{l}\text { Mitsubishi Gas Chemical Co., } \\
\text { Ltd. (Japan) }\end{array}$ & Ageless & $\begin{array}{l}\text { Sachets and } \\
\text { Labels }\end{array}$ & Iron based \\
\hline Toppan Printing Co., Ltd. (Japan) & Fresilizer & Sachets & Iron based \\
\hline Toagosei Chem. Ind. Co. (Japan) & Vitalon & Sachets & Iron based \\
\hline Nippon Soda Co., Ltd. (Japan) & Seaqul & Sachets & Iron based \\
\hline Finetec Co., Ltd. (Japan) & Sanso-cut & Sachets & Iron based \\
\hline Toyo Pulp Co. (Japan) & Tomatsu & Sachets & Catechol \\
\hline Toyo Seikan Kaisha Ltd. (Japan) & Oxyguard & Plastic Trays & Iron based \\
\hline Dessicare Ltd. (US) & O-Buster & Sachets & Iron based \\
\hline \multirow[t]{2}{*}{ Multisorb technologies Inc. (US) } & FreshMax & Labels & Iron based \\
\hline & FreshPax & Sachets & Iron based \\
\hline Amoco Chemicals (US) & Amosorb & Plastic film & Unknown \\
\hline $\begin{array}{l}\text { Ciba Specialty chemicals } \\
\text { (Switzerland) }\end{array}$ & Shelfplus O2 & Plastic film & Iron based \\
\hline \multirow[t]{2}{*}{ W.R. Grace and Co. (US) } & PureSeal & Bottle crowns & Ascorbate/metallic salts \\
\hline & Darex & $\begin{array}{l}\text { Bottle crowns, } \\
\text { bottle }\end{array}$ & Ascorbate/sulphite \\
\hline $\begin{array}{l}\text { CSIRO/Southcorp Packaging } \\
\text { (Australia) }\end{array}$ & Zero2 & Plastic film & $\begin{array}{l}\text { Photosensitive } \\
\text { dye/organic compound }\end{array}$ \\
\hline Cryovac Sealed Air Co. (US) & OS1000 & Plastic film & $\begin{array}{l}\text { Light activated } \\
\text { scavenger }\end{array}$ \\
\hline CMB Technologies (UK) & Oxbar & Plastic bottle & $\begin{array}{l}\text { Cobalt catalyst/nylon } \\
\text { polymer }\end{array}$ \\
\hline \multirow[t]{3}{*}{ Standa Industrie (France) } & ATCO & Sachets & Iron based \\
\hline & Oxycap & Bottle crowns & Iron based \\
\hline & ATCO & Lables & Iron based \\
\hline Bioka Ltd. (Finland) & Bioka & Sachets & Enzyme based \\
\hline
\end{tabular}

Table 1. Some manufacturers and trade names of oxygen scavengers (Ahvenainen and Hurme, 1997; Day, 1998; Vermeiren et al., 1999)

Structurally, the oxygen scavenging component of a package can take the form of a sachet, label, film (incorporation of scavenging agent into packaging film) (Figure 1), card, closure liner or concentrate (Suppakul et al., 2003). 


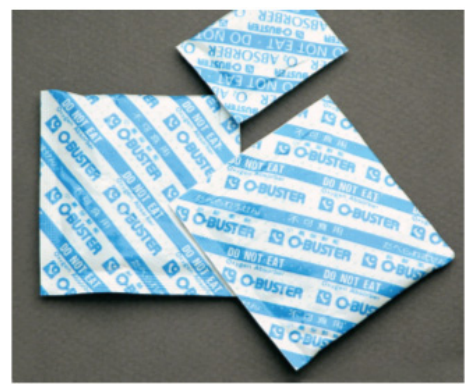

(a)

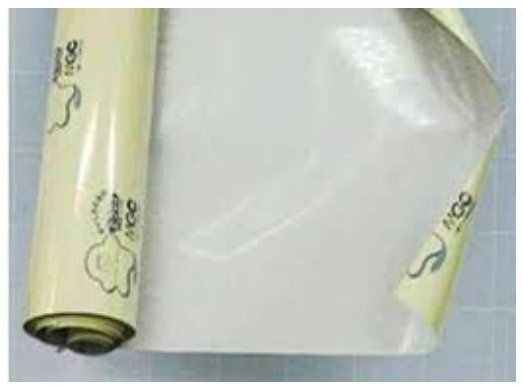

(b)

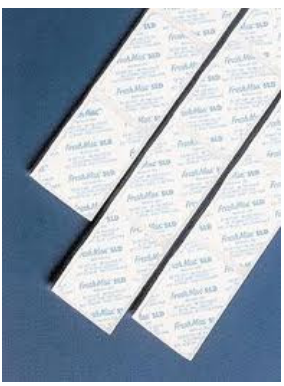

(c)

Figure 1. Oxygen scavengers: (A) O-Buster ${ }^{\circledR}$ sachet, (B) OMAC ${ }^{\circledR}$ film and (C) FreshMax ${ }^{\mathrm{TM}}$ SLD label.

Although the performance of oxygen-absorbing sachets was quite satisfactory for a wide range of food storage conditions, a number of limitations to their use in practice were recognized. The esthetics of inserts, coupled with a concern about possible ingestion or rupture, as well as their unsuitability for use with liquid foods, drove researchers to seek package-based solutions (Rooney, 2005). The incorporation of scavengers in packaging films is a better way of resolving sachet-related problems. Scavengers may either be imbedded into a solid, dispersed in the plastic, or introduced into various layers of the package, including adhesive, lacquer, or enamel layers (Ozdemir and Floros, 2004). In general, the speed and capacity of oxygen-scavenging systems incorporated in the packaging materials are considerably lower than those of (iron-based) oxygen scavenger sachets and labels (Kruijf et al., 2002).

For an oxygen scavenger sachet to be effective, some conditions have to be fulfilled (Nakamura and Hoshino, 1983; Abe, 1994; Smith, 1996). First of all, packaging containers or films with a high oxygen barrier must be used, otherwise the scavenger will rapidly become saturated and lose its ability to trap $\mathrm{O}_{2}$. Films with an oxygen permeability not exceeding 20 $\mathrm{ml} / \mathrm{m}^{2}$.d.atm are recommended for packages in which an oxygen scavenger will be used. Secondly, for flexible packaging heat sealing should be complete so that no air invades the package through the sealed part. Finally, an oxygen scavenger of the appropriate type and size must be selected. The appropriate size of the scavenger can be calculated using the following formulae (Roussel, 1999; ATCO $^{\circledR}$ technical information, 2002). The volume of oxygen present at the time of packaging $(A)$ can be calculated using the formula:

$$
\mathrm{A}=\frac{(\mathrm{V}-\mathrm{P}) \times\left[\mathrm{O}_{2}\right]}{100}
$$

where $V$ is the volume of the finished pack determined by submission in water and expressed in $\mathrm{ml}, P$ is the weight of the finished pack in $\mathrm{g}$ and $\left[\mathrm{O}_{2}\right]$ is the initial $\mathrm{O}_{2}$ concentration in package $(=21 \%$ if air $)$.

In addition, it is necessary to calculate the volume of oxygen likely to permeate through the packaging during the shelf-life of the product $(B)$. This quantity in $\mathrm{ml}$ may be calculated as follows: 


$$
\mathrm{B}=\mathrm{S} \times \mathrm{P} \times \mathrm{D}
$$

where $S$ is the surface area of the pack in $\mathrm{m}^{2}, P$ is the permeability of the packaging in $\mathrm{ml} / \mathrm{m}^{2} / 24 \mathrm{~h} / \mathrm{atm}$ and $D$ is the shelf-life of the product in days.

The volume of oxygen to be absorbed is obtained by adding $A$ and $B$. Based on these calculations, the size of the scavenger and the number of sachets can be determined.

According Cruz et al. (2005), the scavengers may be used alone or combined with modified atmosphere. This association requires the equipments to apply the modified atmosphere and decreases the filling velocity. However, this technique is generally used in the market to reduce the oxygen to desirable levels.

Oxygen scavengers have attracted interest of food researchers, and then in this chapter we will discuss the principles involved in scavenge of $\mathrm{O}_{2}$, as well the main applications and researches in this field of active food packaging.

\section{Oxygen scavengers systems}

Nowadays, there are many systems of oxygen scavengers based on metallic and nonmetallic coumpounds. The mechanism of each system is described below.

\subsection{Iron powder oxidation}

The commercially oxygen scavengers available are in form of small sachets containing metallic reducing agents, such as powder iron oxide, ferrous carbonate and metallic platinum. The majority of these scavengers are based on the principle of iron oxidation in water presence. A self-reacting type contains moisture in the sachet and as soon as the sachet is exposed to air, the reaction starts. In moisture-dependent types, oxygen scavenging takes place only after moisture has been taken up from the food. These sachets are stable in open air before use because they do not react immediately upon exposure to air therefore they are easy to handle if kept dry (Vermeiren et al., 1999; Cruz et al., 2005). The action mechanism of oxygen scavenger based on iron oxidation is very complicated and is described by the following reactions.

$$
\begin{gathered}
\mathrm{Fe} \rightarrow \mathrm{Fe}^{2+}+2 \mathrm{e}^{-} \\
\frac{1}{2} \mathrm{O}_{2}+\mathrm{H}_{2} \mathrm{O}+2 \mathrm{e}^{-} \rightarrow 2 \mathrm{OH}^{-} \\
\mathrm{Fe}^{2+}+2 \mathrm{OH}^{-} \rightarrow \mathrm{Fe}(\mathrm{OH})_{2} \\
\mathrm{Fe}(\mathrm{OH})_{2}+\frac{1}{4} \mathrm{O}_{2}+\frac{1}{2} \mathrm{H}_{2} \mathrm{O} \rightarrow \mathrm{Fe}(\mathrm{OH})_{3}
\end{gathered}
$$

According Shorter (1982), if the oxidation rate of the food product and the oxygen permeability of the packaging were known, it is possible to calculate the required iron amount to maintain the desirable oxygen level during the storage time. A rule of thumb is 
that $1 \mathrm{~g}$ of iron will react with $300 \mathrm{ml}$ of $\mathrm{O}_{2}$ (Labuza, 1987; Nielsen, 1997; Vermeiren et al., 1999). The LD 50 (lethal dose that kills $50 \%$ of the population) for iron is $16 \mathrm{~g} / \mathrm{kg}$ body weight. The largest commercially available sachet contains 7 grams of iron so this would amount to only $0.1 \mathrm{~g} / \mathrm{kg}$ for a person of $70 \mathrm{~kg}$, or 160 times less than the lethal dose (Labuza and Breene, 1989).

Cruz et al. (2007) evaluate the efficiency of O-Buster ${ }^{\circledR}$ oxygen - absorbing sachets at relative humidity of $75 \%, 80 \%$ and $85 \%$ and different temperatures, $10 \pm 2{ }^{\circ} \mathrm{C}$ and $25 \pm 2{ }^{\circ} \mathrm{C}$. They observed that oxygen absorption by the sachet increased as the relative humidity increased for both temperature. Therefore the oxygen - absorbing sachets were most active under $25 \pm$ $2{ }^{\circ} \mathrm{C}$ and $85 \%$ relative humidity. At ambient condition $\left(25 \pm 2{ }^{\circ} \mathrm{C} / 75 \% \mathrm{RH}\right)$ the rate of oxygen absorbed was $50 \mathrm{ml} /$ day and $18.5 \mathrm{ml} /$ day for $10 \pm 2^{\circ} \mathrm{C}$.

Some important iron-based $\mathrm{O}_{2}$ absorbent sachets are Ageless ${ }^{\circledR}$ (Mitsubishi Gas Chemical Co., Japan), $\mathrm{ATCO}^{\circledR} \mathrm{O} 2$ scavenger (Standa Industrie, France), Freshilizer ${ }^{\circledR}$ Series (Toppan Printing Co., Japan), Vitalon (Toagosei Chem. Industry Co., Japan), Sanso-cut (Finetec Co., Japan), Seaqul (Nippon Soda Co., Japan), FreshPax ${ }^{\circledR}$ (Multisorb technologies Inc., USA) and O-Buster ${ }^{\circledR}$ (Dessicare Ltd., USA).

\subsection{Ascorbic acid oxidation}

The ascorbic acid is another oxygen scavenger component which action based on ascorbate oxidation to dehydroascorbic acid. Most of these reactions is slow and can be accelerated by light or a transition metal which will work as catalyst, e.g., the copper (Cruz et al, 2005).

The ascorbic acid reduce the $\mathrm{Cu}^{2+}$ to $\mathrm{Cu}^{+}$to form the dehydroascorbic acid (Equation I). The cuprous ions $\left(\mathrm{Cu}^{+}\right)$form a complex with the $\mathrm{O}_{2}$ originating the cupric ion $\left(\mathrm{Cu}^{2+}\right)$ and the superoxide anionic radical (Equation II). In copper presence, the radical leads to formation of $\mathrm{O}_{2}$ and $\mathrm{H}_{2} \mathrm{O}_{2}$ (Equation III). The copper-ascorbate complex quickly reduces the $\mathrm{H}_{2} \mathrm{O}_{2}$ to $\mathrm{H}_{2} \mathrm{O}$ (Equation IV) without the $\mathrm{OH}^{-}$formation, a highly reactive oxidant. The following reactions show the process of oxygen absorber by ascorbic acid.

$$
\begin{gathered}
\mathrm{AA}+2 \mathrm{Cu}^{2+} \rightarrow \mathrm{DHAA}+2 \mathrm{Cu}^{+}+2 \mathrm{H}^{+} \\
2 \mathrm{Cu}^{+}+2 \mathrm{O}_{2} \rightarrow 2 \mathrm{Cu}^{2+}+2 \mathrm{O}_{2}^{-} \\
2 \mathrm{O}_{2}^{-}+2 \mathrm{H}^{+}+\mathrm{Cu}^{2+} \rightarrow \mathrm{O}_{2}+\mathrm{H}_{2} \mathrm{O}_{2}+\mathrm{Cu}^{2+} \\
\mathrm{H}_{2} \mathrm{O}_{2}+\mathrm{Cu}^{2+}+\mathrm{AA} \rightarrow \mathrm{Cu}^{2+}+\text { DHAA }+2 \mathrm{H}_{2} \mathrm{O}
\end{gathered}
$$

These equations can be summarized as described below:

$$
\mathrm{AA}+\frac{1}{2} \mathrm{O}_{2} \rightarrow \mathrm{DHAA}+\mathrm{H}_{2} \mathrm{O},
$$

where AA is the ascorbic acid and DHAA is the dehydroascorbic acid.

The total capacity of the $\mathrm{O}_{2}$ absorption is determined by the amount of ascorbic acid. The complete reducing of $1 \mathrm{~mol}$ of $\mathrm{O}_{2}$ requires 2 moles of ascorbic acid (Cruz et al., 2005). 
Ascorbic acid and ascorbate salts are being used in the design of scavengers in both sachet and film technologies. A patent from Pillsbury describes the oxygen-reducing properties of these substances. The active film may contain a catalyst, commonly a transition metal $(\mathrm{Cu}$, $\mathrm{Co}$ ), and it is activated by water; therefore, this technology is specially indicated for aqueous food products, or when the packaged product is sterilized because the water vapor inside the autoclave is capable of triggering the scavenging process (Brody et al., 2001a).

\subsection{Enzymatic oxidation (e.g., glucose oxidase and alcohol oxidase)}

Some $\mathrm{O}_{2}$-scavengers use a combination of two enzymes, glucose oxidase and catalase, that would react with some substrate to scavenge incoming $\mathrm{O}_{2}$. The glucose oxidase transfers two hydrogens from the $-\mathrm{CHOH}$ group of glucose, that can be originally present or added to the product, to $\mathrm{O}_{2}$ with the formation of glucono-delta-lactone and $\mathrm{H}_{2} \mathrm{O}_{2}$. The lactone then spontaneously reacts with water to form gluconic acid (Labuza and Breene, 1989; Nielsen, 1997). A negative factor of this process is the catalase presence, a natural contaminant found in the glucose oxidase preparation, since the catalase reacts with the $\mathrm{H}_{2} \mathrm{O}_{2}$ forming $\mathrm{H}_{2} \mathrm{O}$ and $\mathrm{O}_{2}$ and, therefore, decreasing the system efficiency. However, the glucose oxidase production without catalase is so expensive. The reactions can be expressed as follows:

$$
2 \text { glucose }+2 \mathrm{O}_{2}+2 \mathrm{H}_{2} \mathrm{O} \rightarrow 2 \text { gluconic acid }+2 \mathrm{H}_{2} \mathrm{O}_{2}
$$

where glucose is the substrate.

Since $\mathrm{H}_{2} \mathrm{O}_{2}$ is an objectionable end product, catalase is introduced to break down the peroxide (Brody and Budny, 1995):

$$
2 \mathrm{H}_{2} \mathrm{O}_{2}+\text { catalase } \rightarrow 2 \mathrm{H}_{2} \mathrm{O}+\mathrm{O}_{2}
$$

According the reaction, $1 \mathrm{~mol}$ of glucose oxidade reacts with $1 \mathrm{~mol}$ of $\mathrm{O}_{2}$. So, in an impermeable packaging with $500 \mathrm{ml}$ of headspace only $0.0043 \mathrm{~mol}$ of glucose $(0.78 \mathrm{~g})$ is necessary to obtain $0 \%$ of $\mathrm{O}_{2}$. The enzymatic efficiency depends on the enzymatic reaction velocity, the substrate amount and the oxygen permeability of the packaging.

Coupled enzyme systems are very sensitive to changes in $\mathrm{pH}$, $\mathrm{a}_{\mathrm{w}}$, salt content, temperature and various other factors. Additionally, they require the addition of water and, therefore, cannot be effectively used for low-water foodstuffs (Graff, 1994). One application for glucose oxidase is the elimination of $\mathrm{O}_{2}$ from bottled beer or wine. The enzymes can either be part of the packaging structure or put in an independent sachet. The immobilization occurs by different process, such as, adsorption and encapsulation. Both polypropylene (PP) and polyethylene (PE) are good substrates for immobilizing enzymes (Labuza and Breene, 1989). A commercially available $\mathrm{O}_{2}$-removing sachet based on reactions catalyzed by food-grade enzymes is the Bioka $\mathrm{O}_{2}$-absorber (Bioka, Finland). It is claimed that all components of the reactive powder and the generated reaction products are food-grade substances safe for both the user and the environment (Bioka technical information, 1999). The oxygen scavenger eliminates the oxygen in the headspace of a package and in the actual product in 12-48 hours at $20^{\circ} \mathrm{C}$ and in $24-96$ hours at $2-6^{\circ} \mathrm{C}$. With certain restrictions, the scavenger 
can also be used in various frozen products. When introducing the sachet into a package, temperature may not exceed $60^{\circ} \mathrm{C}$ because of the heat sensitivity of the enzymes (Bioka technical information, 1999). An advantage is that it contains no iron powder, so it presents no problems for microwave applications and for metal detectors in the production line.

Besides glucose oxidase, other enzymes have potential for $\mathrm{O}_{2}$-scavenging, including ethanol oxidase which oxidises ethanol to acetaldehyde. It could be used for food products in a wide aw range since it does not require water to operate. If a lot of oxygen has to be absorbed from the package, a great amount of ethanol would be required, which could cause an offodour in the package. In addition, considerable aldehyde would be produced which could give the food a yoghurt-like odour (Labuza and Breene, 1989).

\subsection{Unsaturated hydrocarbon oxidation}

The oxidation of polyunsaturated fatty acids (PUFAs) is another technique to scavenge oxygen. It is an excellent oxygen scavenger for dry foods. Most known oxygen scavengers have a serious disadvantage: when water is absent, their oxygen scavenging reaction does not progress. In the presence of an oxygen scavenging system, the quality of the dry food products may decline rapidly because of the migration of water from the oxygen scavenger into the food. Mitsubishi Gas Chemical Co. holds a patent that uses PUFAs as a reactive agent. The PUFAs, preferably oleic, linoleic or linolenic, are contained in carrier oil such as soybean, sesame or cottonseed oil. The oil and/or PUFA are compounded with a transition metal catalyst and a carrier substance (for example calcium carbonate) to solidify the oxygen scavenger composition. In this way the scavenger can be made into a granule or powder and can be packaged in sachets (Floros et al., 1997).

In many patent applications (Ackerley et al., 1998; Akkapeddi and Tsai, 2002; Barski et al., 2002; Cahill and Chen, 2000; Goodrich et al., 2003; Kulzick et al., 2000; Mize et al., 1996; Morgan et al., 1992; Roberts et al., 1996; Speer and Roberts, 1994; Speer et al., 2002), it was disclosed that ethylenic-unsaturated hydrocarbons, such as squalene, fatty acids, or polybutadiene, had sufficient commercial oxygen scavenging capacity to extend the shelflife of oxygen-sensitive products. These unsaturated hydrocarbons, after being functionally terminated with a chemical group to make them compatible with the packaging materials, can be added during conventional mixing processes to thermoplastics such as polyesters, polyethylene, polypropylene, or polystyrene, and the films can be obtained using most conventional techniques for the plastic processing such as coinjection or coextrusion. 1,2Polybutadiene is specially preferred because it exhibits transparency, mechanical properties, and processing characteristics similar to those of polyethylene. In addition, this polymer is found to retain its transparency and mechanical integrity, and exhibits a high oxygenscavenging capacity (Roberts et al., 1996). Transition metal catalysts, such as cobalt II neodecanoate or octoate (Barski et al., 2002; Mize et al., 1996; Speer et al., 2002), are also included in the oxygen scavenger layer in order to accelerate the scavenging rate. Photoinitiators can also be added to further facilitate and control the initiation of the scavenging process. Adding a photoinitiator or a blend of photoinitiators to the oxygen- 
scavenging composition is a common practice, especially where antioxidants were added to prevent premature oxidation of the composition during processing and storage.

The main problem of this technology is that during the reaction between these polyunsaturated molecules and oxygen, by-products such as organic acids, aldehydes, or ketones can be generated that affect the sensory quality of the food or raise food regulatory issues (Brody et al., 2001a). Indeed, some of these compounds are used to determine the quality and shelf-life of fatty foodstuffs because they are intrinsically related to rancidity (Jo et al., 2002; Van Ruth et al., 2001). This problem can be minimized by the use of functional barriers that impede migration of undesirable oxidation products. This functional layer must provide a high barrier to organic compounds, but allow oxygen to migrate, and it has to be inserted between the food product and the scavenger layer. Another solution comes from the use of adsorber materials. Some polymers present inherent organic compound-scavenging properties. Others incorporate adsorbers within the polymer structure (i.e., silica gel, zeolites, etc). It has also been found that when the ethylenic unsaturation is contained within a cyclic group, substantially fewer by-products are produced upon oxidation as compared with analogous noncyclic materials. The Oxygen Scavenging Polymer developed by Chevron Chemical is an example of this kind of technology. This system is reported to scavenge oxygen without degrading into smaller, undesirable compounds. Ten percent of the polymer is a concentrate that contains a photoinitiator plus a transition metal catalyst that maintains the polymer in a nonscavenging state until triggered by ultraviolet (UV) radiation (Rooney, 1995).

Oxbar $^{\mathrm{TM}}$ is a system developed by Carnaud-Metal Box (now Crown Cork and Seal) that involves cobalt-catalyzed oxidation of a MXD6 nylon that is blended into another polymer. This system is used especially in the manufacturing of rigid PET bottles for packaging of wine, beer, flavored alcoholic beverages, and malt-based drinks (Brody et al., 2001b).

Another $\mathrm{O}_{2}$ scavenging technology involves using directly the closure lining. Darex ${ }^{\circledR}$ Container Products (now a unit of Grace Performance Chemicals) has announced an ethylene vinyl alcohol with a proprietary oxygen scavenger developed in conjunction with Kararay Co. Ltd. In dry forms, pellets containing unsaturated hydrocarbon polymers with a cobalt catalyst are used as oxygen scavengers in mechanical closures, plastic and metal caps, and steel crowns (both PVC and non-PVC lined). They reportedly can prolong the shelf life of beer by $25 \%$ (Brody et al., 2001b).

\subsection{Immobilization of microorganisms in solid holders}

At least two patents from the 1980s and 1990s describe the use of yeast to remove oxygen from the headspace of hermetically sealed packages. One patent, from enzyme manufacturer Gist Brocades, focused on the incorporation of immobilized yeast into the liner of a bottle closure (Edens et al., 1992). The other patent used the yeast in a pouch within the package (Nezat, 1985). The concept of the patents was that, when moistened, the yeast is activated and respires, consuming oxygen and producing carbon dioxide plus alcohol. In the bottleclosure application, any carbon dioxide and alcohol produced would enter the contents, in this case beer, without causing measurable changes in the product. 
Other researchers proposed an alternative approach: the use of entrapped aerobic microorganisms, capable of consuming oxygen (Tramper et al., 1983; Doran and Bailey, 1986; Gosmann and Rehem, 1986 and Gosmann \& Rehem 1988). Natural and biological oxygen scavengers, based on the use of microorganisms entrapped in a polymeric matrix, effective in preserving foods, safe to use, agreeable to consumer, inexpensive, environment friendly, could be a very interesting concept to modern food technology. In fact, the possibility to create a new package, having many desirable characteristics, is very promising, also taking into account the new consumers' demand for mildly preserved convenience foods, having fresh-like qualities and being environmental friendly. In the field of biotechnology, immobilization of whole cells is gaining increasing importance (Gosmann and Rehem, 1988). Alginate, agar, and gelatin (Tramper et al., 1983; Doran and Bailey, 1986; Gosmann and Rehem, 1986 and Gosmann and Rehem, 1988) have been successfully used. Unfortunately, the above study cannot be used for the development of a biological oxygenscavenger. In fact, the cycle life of a biological oxygen-scavenger film includes the entrapment of the microorganisms in an appropriate polymeric matrix (film manufacturing), the maintenance of the desiccated film till its use (film storage and distribution), and the rehydration (film usage, obtained by putting the film in contact with the food).

Altiere et al. (2004) develop an environmental friendly oxygen-scavenger film using microorganisms as the active component. In particular, hydroxyethyl cellulose (HEC) and polyvinyl alcohol (PVOH) were used to entrap two different kinds of microorganisms: Kocuria varians and Pichia subpelliculosa. In this work a new method is proposed to produce oxygen-scavenger films using aerobic microorganisms as the "active compound". The manufacturing cycle of the investigated oxygen-scavenger film was optimized both to prolong the microorganisms viability during storage and to improve the efficiency of the film to remove oxygen from the package headspace. It was found that it is possible to store the desiccated film over a period of 20 days without monitoring any appreciable decrease of microorganism viability. It was also pointed out that the highest respiratory efficiency of the proposed active film is obtained by entrapping the microorganisms into polyvinyl alcohol, and by using the active film as a coating for a high humidity food.

\subsection{Photosensitive dye oxidation}

Another technique of oxygen absorption is a photosensitive dye impregnated onto a polymeric film. When the film is irradiated by ultraviolet (UV) light, the dye activates the $\mathrm{O}_{2}$ to its singlet state, making the oxygen-removing reaction much faster (Ohlsson and Bengtsson, 2002).

Australian researchers have reported that reaction of iron with ground state $\mathrm{O}_{2}$ is too slow for shelf-life extension. The singletexcited state of oxygen, which is obtained by dye sensitisation of ground state oxygen using near infra-red, visible or ultraviolet radiation, is highly reactive and so its chemical reaction with scavengers is rapid. The technique involves sealing of a small coil of ethyl cellulose film, containing a dissolved photosensitising dye and a singlet oxygen acceptor, in the headspace of a transparent package. When the film is 
illuminated with light of the appropriate wavelength, excited dye molecules sensitise oxygen molecules, which have diffused into the polymer, to the singlet state. These singlet oxygen molecules react with acceptor molecules and are thereby consumed. The photochemical reaction can be presented as follows (Vermeiren et al., 2003, Cruz et al., 2005).

$$
\begin{gathered}
\text { photon }+ \text { dye } \rightarrow \text { dye* } \\
\text { dye* }+\mathrm{O}_{2} \rightarrow \text { dye }+\mathrm{O}_{2}^{*} \\
\mathrm{O}_{2}^{*}+\text { acceptor } \rightarrow \text { acceptor oxide }
\end{gathered}
$$

This scavenging technique does not require water as an activator, so it is effective for wet and dry products. Its scavenging action is initiated on the processor's packaging line by an illumination-triggering process (Vermeiren et al., 2003).

Cryovac ${ }^{\circledR}$ 0S2000 ${ }^{\mathrm{TM}}$ polymer based oxygen scavenging film has been developed by Cryovac Div., Sealed Air Corporation, USA. This UV light-activated oxygen scavenging film (Figure 2), composed of an oxygen scavenger layer extruded into a multilayer film, can reduce headspace oxygen levels from $1 \%$ to ppm levels in 4-10 days and is comparable in effectiveness with oxygen scavenging sachets. The OS2000 ${ }^{\mathrm{TM}}$ scavenging films have applications in a variety of food products including dried or smoked meat products and processed meats (Butler, 2002).

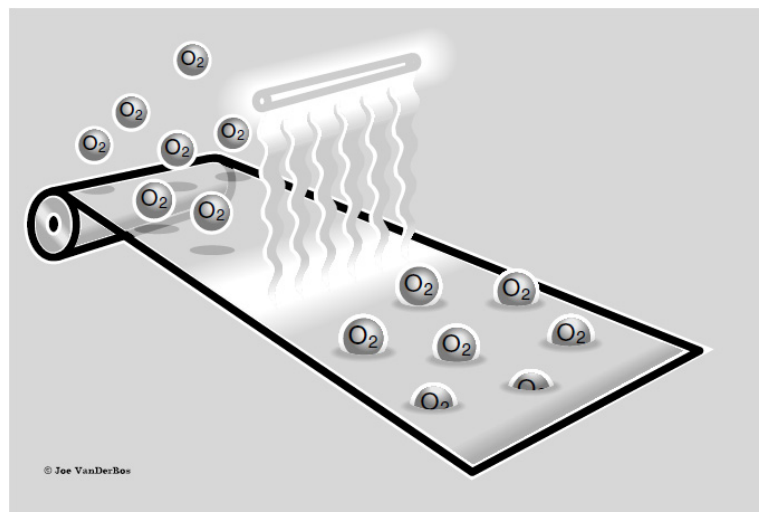

Figure 2. Light-activated oxygen scavenging films Cryovac ${ }^{\circledR}$ OS Films (Cryovac Food Packaging, Sealed Air Corporation, USA).

A similar UV light-activated oxygen scavenging polymer $\mathrm{ZERO}_{2}{ }^{\circledR}$, developed by CSIRO, Division of Food Science Australia in collaboration with Visy Pak Food Packaging, Visy Industries, Australia, forms a layer in a multilayer package structure and can be used to reduce discoloration of sliced meats. The active ingredient of the $\mathrm{ZERO}_{2}{ }^{\circledR}$ is integrated into the polymer backbones of such common packaging materials as PET, polyethylene, polypropylene and EVA. The active ingredient is nonmetallic and is activated by UV light once it is incorporated into packaging material (Graff, 1998). 
Another successful commercial example for use with meat is the OSPTM system (Chevron Philips Chemical Company, USA). The active substances of OSPTM systems are ethylene methacrylate and cyclohexene methacrylate, which need to be blended with a catalyst or photoinitiator in order to activate the oxygen scavenging mechanism.

\subsection{Others}

Sulphites have also been proposed as active substances for use, not only in sachets, but also in plastic gasket liners of bottle closures, as liquid trapped between sheets of flexible packaging material, or directly incorporated into plastic film structures to pack products such as wine or ketchup. For example, potassium sulfite is cited as an $\mathrm{O}_{2}$ scavenger that can be readily triggered by the moist high temperature of the retorting process, and it also has enough thermal stability to pass unchanged through thermoplastic processes. However, any oxygen scavenger producing an end-product compound such as sulfur dioxide is viewed with concern because these by-products can exert a sensory change, or even an allergic effect on a susceptible consumer (Brody et al., 2001a).

Antioxidants, incorporated into flexible and thermoformable plastic packaging materials, are intended to reduce oxygen passage through the plastic structure or to remove oxygen from packages containing dry food products such as breakfast cereals (Floros et al., 1997). Butylated hydroxytoluene (BHT), a commonly used plastic antioxidant, has been proven to prolong the shelf-life of packed oat flakes (Miltz et al., 1989), but there is some concern related to the physiological effects of consuming it because it seems that BHT tends to accumulate in the adipose tissue (Wessling et al., 1998).

Nowadays, tendencies lead toward natural products and, therefore, natural antioxidants are being explored. There are a number of naturally occurring compounds that have antioxidant properties, including tocopherols, lecithin, organic acids and rosemary extracts. Among them, there is a growing interest in the use of vitamin $\mathrm{E}$ (also known as a-tocopherol) and vitamin $\mathrm{C}$ to be incorporated into polymers. Vitamin $\mathrm{E}$ has been marketed as a food-grade odor remover in packaging materials. For example, Laermer et al. (1996) showed that addition of vitamin $\mathrm{E}$ to high density polyethylene (HDPE)-ethylene/vinyl acetate (EVA)HDPE flexible packaging system could reduce the "plastic" taste and preserve the fresh taste of breakfast cereals. Ho et al. (1994) showed that vitamin E was effective in reducing off-flavor compounds released from HDPE bottles. Vitamin E has somehow superior antioxidant behavior than BHT related to the off-flavor generation, stability and solubility, in polyolefins. The incorporation of vitamins $\mathrm{E}$ or $\mathrm{C}$ into the plastic material presents another advantage when compared with the addition of synthetic antioxidants because the possible migration of these compounds into the food not only does not produce adverse effects, but also improves the nutritional characteristics of the food product. However, being a bigger molecule than BHT, it is less mobile (Wessling et al., 1998). The amount of antioxidant added to the polymer must be controlled, as high levels of antioxidant incorporated into films can alter the polymer properties. Oxygen permeability of the film would increase and somemechanical properties of the film would change (Wessling, 2000). 
Many patents have been issued for UV light activated oxygen scavengers, however, these UV activation steps reduces packaging line speeds and resulting in reduced profitability. In addition, there is a significant cost increases for oxygen scavenging films due to the high cost of photoinitiators and the operation and maintenance costs of the UV machine. Therefore the development of new oxygen scavenging systems that don' $t$ require a UV activation step should be valuable to the food packaging industry.

Oxygen scavenging systems that utilise natural compounds as the basis for the oxygen scavenger may provide added benefit. One such potential compound is $\alpha$-tocopherol which is a natural free radical scavenger with a positive consumer perception (Hamilton et al., 1997). It has been incorporated into the polymer materials as a stabilizer (Al-Malaika et al., 1999) and as an antioxidant in controlled release packaging to reduce the oxidation in food products (Byun et al., 2010, Lacoste et al., 2005, Siro et al., 2006 and Wessling et al., 2000).

The oxygen scavenging principle for the use of $\alpha$-tocopherol was that oxygen free radicals can be produced by a transition metal. Oxygen free radicals are derived from the non-enzymatic reactions of oxygen along with transition metals (Bagchi and Puri, 1998). The transition metal activates oxygen to the singlet electron state oxygen. Then, this activated oxygen undergoes subsequent reduction to reactive oxygen species (ROS), which is an oxygen free radical. $\alpha$ Tocopherol is a strong free radical scavenger which can also react irreversibly with singlet oxygen and produce tocopherol hydroperoxydienone, tocopherylquinone, and quinine epoxide (Choe and Min, 2006). $\alpha$-Tocopherol can donate its electrons to scavenge the oxygen free radical. When the free radical gains the electron from $\alpha$-tocopherol, it returns to its ground state and the free radical is eliminated.

There are two chemical reaction steps in this oxygen scavenging reaction as follow. In first step, oxygen free radicals are produced in the presence of a transition metal. In the second step, the oxygen free radicals are eliminated by receiving electrons from $\alpha$-tocopherol (Smirnoff, 2005). Therefore, the presence of both the transition metal and $\alpha$-tocopherol are essential conditions for the oxygen scavenging system. Furthermore, thermal processing can accelerate oxygen scavenging reaction.

$$
\text { Initiation step: Oxygen }+ \text { transition metal } \stackrel{\Delta}{\rightarrow} \text { oxygen free radical }
$$

Scavenging step: $\alpha$ - tocopherol + oxygen free radical $\rightarrow$ dimer or tocopherylquinone

\section{Practical application and researches}

Oxygen scavengers have been studied for many researchers. There are many different types of oxygen scavengers that have been successfully applied to reducing food spoilage. In this section, we will discuss about the main and recent studies involving this technology.

Acid ascorbic is degraded to dehidroascorbic acid in the presence of oxygen, and the rate at which dehydroascorbic acid is formed is approximately first order with respect to the concentrations of ascorbic acid, oxygen, and metal catalysts. To evaluate the ascorbic acid loss in orange juice due to oxygen presence, the product was packed in oxygen scavenging 
film and oxygen barrier film. The initial concentration of ascorbic acid in the orange juice was $374 \mathrm{mg} / \mathrm{l}$ and this decreased by 74 and $104 \mathrm{mg} / \mathrm{l}$ after 3 days of storage at $25{ }^{\circ} \mathrm{C}$ in the $\mathrm{O}_{2}$ scavenger film and $\mathrm{O}_{2}$ barrier film, respectively. The rapid loss in ascorbic acid was related to the high oxygen content initially present in the headspace and that dissolved in the juice. This content of oxygen could not be eliminated by $\mathrm{O}_{2}$ barrier film. The authors concluded that the rapid removal of oxygen is an important factor to maintain the ascorbic acid content in orange juice over long storage times (Zerdin et al., 2003).

Altieri et al. (2004) purposed a new method to produce oxygen-scavenger film based on aerobic microorganisms (Kocuria varians and Pichia subpelliculosa). These microorganisms were entrapped into hydroxyethyl cellulose and polyvinyl alcohol and maintained their viability over 20 days. Both films were able to reduce oxygen content present into vials, however the highest respiratory efficient was obtained by entrapping the microorganism into polyvinyl alcohol.

Mohan et al. (2009) studied the effect of commercial oxygen scavenger in reducing the formation of biogenic amines during chilled storage of fish. It was observed that the $\mathrm{O}_{2}$ scavenger was able to reducing the oxygen content of the pack up to $99.95 \%$ within $24 \mathrm{~h}$ and it extended the fish shelf-life up to 20 days compared to only 12 days for air packs. The biogenic amine content was significantly higher in air packs compared to the $\mathrm{O}_{2}$ scavenger packs. Inhibition of enzymatic activity of food or bacterial decarboxylase activity and prevention of bacterial growth are essential to control the production of biogenic amine. The authors verified that the use of oxygen scavengers associated to chilled storage temperature helps in reducing the formation of biogenic amines in fish. In conclusion, the authors believe that by using $\mathrm{O}_{2}$ scavengers, use of vacuum packing machine can be avoided.

The health benefits of the Mediterranean diet are often related to the consumption of olive oil. The container material has been related to influence the oi quality and sensorial characteristics. Glass is the most used material, however the use of polyethylene terephthalate (PET) bottle have increased, since it is transparent, recyclable, unbreakable, inexpensive and it has demonstrated the ability to preserve the characteristics of olive oil during its shelf-life. In the other hand, the permeability of the PET bottle to gases and vapour, such as oxygen limits the use of these containers to olive oil, since rancidity is the main cause of oil spoilage. In this context, Cecchi et al. (2010) evaluated the quality of extravirgin olive oil packed into PET bottles containing or not commercial oxygen scavenger. Results of the 13-months experimental study indicate that the presence of the $\mathrm{O}_{2}$ scavenger in the plastic matrix was able to better maintain the quality and authenticity attributes of the oil. A reduced flux of oxygen through the PET bottle keeps the level of primary and secondary oxidation products lower than that obtained in simple PET bottles stored under the same conditions. The active barrier reduces the olive oil antioxidant activity decline during storage. The chlorophylls content decay can only be prevented via the storage of the sample in the dark, while the active barrier is able to diminish the carotenes loss at the end of the shelf-life. On the whole, the performance of the tested innovative packageing proved to better preserve the extra virgin characteristics of the oil during its shelf-life. 
A variety of oxygen scavengers have been commercialised for use in the food packaging industry. These oxygen scavenging system are used in various forms such as; sachets, plastic films, labels, plastic trays, and bottle crowns. The most used $\mathrm{O}_{2}$ scavengers are based on the principle of iron oxidation.

Cruz et al. (2006) evaluated an $\mathrm{O}_{2}$ absorbent system on the inhibition of microorganisms growth in fresh lasagna pasta during storage at $10 \pm 2^{\circ} \mathrm{C}$. Fresh lasagna pasta was produced with and without potassium sorbate and acondicionated in high $\mathrm{O}_{2}$ barrier bags containing an $\mathrm{O}_{2}$-absorber sachet in the headspace. Three treatments were obtained: pasta with potassium sorbate, pasta without potassium sorbate packed with sachet and pasta without potassium sorbate packed without sachet (Figure 3). Oxygen absorbers were efficient in controlling the growth of filamentous fungi and yeasts, Staphylococus spp, total coliforms and E. coli in lasagna type fresh pasta without the addition of potassium sorbate, vacuumpacked in $\mathrm{O}_{2}$-absorbent sachets, stored at $10 \pm 2{ }^{\circ} \mathrm{C}$. Therefore, the $\mathrm{O}_{2}$-absorber sachet can be used as a hurdle technology, associated with vacuum packaging and applying the good manufacturing practices, to preserve lasagna pasta without additives.

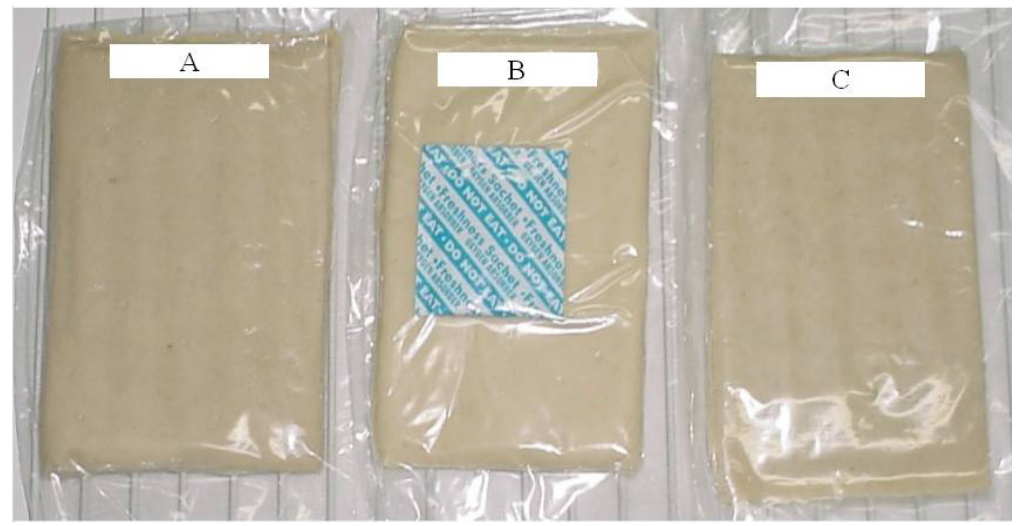

Figure 3. Fresh lasagna pasta vacuum-packed with potassium sorbate (A), without potassium sorbate and with oxygen scavenger (B) and without potassium sorbate.

However, nowadays, many consumers have a negative view of the term "iron-based." Therefore, Byun et al. (2011) studied the development of na oxygen scavenger using a natural compound: $\alpha$-tocopherol. A natural free radical scavenger, $\alpha$-tocopherol, and a transition metal in an oxygen scavenging system were evaluated as a possible oxygen scavenger. An initial, cup headspace oxygen content (\%) of $20.9 \%$ was decreased to $18.0 \%$ after thermal processing and 60 days of storage at room temperature when the oxygen scavenging system containing $\alpha$-tocopherol (500 mg) and transition metal (100 mg) was utilised. The oxygen content (\%) decreased further to $17.1 \%$ when the amount of transition metal increased from 100 to $150 \mathrm{mg}$. The authors concluded that $\alpha$-tocopherol (500 mg) and transition metal $(150 \mathrm{mg}$ ) had an oxygen scavenging capacity of $6.72 \mathrm{ml} \mathrm{O} / \mathrm{g}$ and an oxygen scavenging rate of $0.11 \mathrm{ml} \mathrm{O} 2 / \mathrm{g} \bullet$ day. 
Others authors also research alternative systems able to scavenging oxygem. Anthierens et al. (2011) developed an $\mathrm{O}_{2}$ scavenger using an endospore-forming bacteria genus Bacillus amyloliquefaciens as the "active ingredient". Spores were incorporated in poly(ethylene terephthalate, 1,4-cyclohexane dimethanol) (PETG), na amorphous PET copolymer having a considerable lower processing temperature and higher moisture absorption compared to PET (Figure 4). The work showed that endospores were able to survive incorporation in PETG at $210{ }^{\circ} \mathrm{C}$, and the spores could consume oxygen for minimum 15 days, after na activation period of 1-2 days at $30{ }^{\circ} \mathrm{C}$ under high moisture conditions. According to the authors, the usse of viable spores as oxygen scavengers could have advantages towards consumer perception, recyclability, safety, material compatibility and production costs compared to currently available chemical oxygen scavengers.

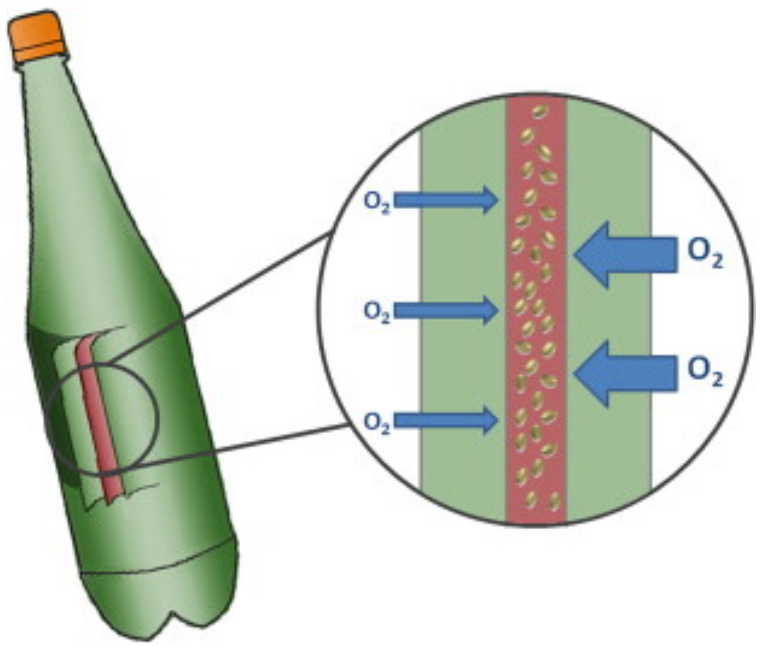

Figure 4. Schematic representation of a multilayer PET bottle consisting of a PETG middle layer containing bacterial spores surrounded by two outer PET layers. The inside of the bottle is in contact with the product, allowing moisture uptake of the bottle needed for spore germination. The system allows scavenging of residual oxygen from the in-bottle environment and scavenging from atmospheric oxygen permeating through the bottle wall (Anthierens et al., 2011)

An ascorbyl palmitate- $\beta$-cyclodextrin inclusion complex was produced and used as oxygen scavenger by Byun and Whiteside (2012). Cyclodextrin inclusion complex is one microencapsulation technique that has a significant potential for oxygen scavenging technology. Cyclodextrins (CDs) are cyclic oligosaccharides with a hydrophilic exterior and a hydrophobic central cavity. Its molecular dimensions allow total or partial inclusion of guest compounds. Among conventional microencapsulation methods, $\beta$-cyclodextrin inclusion is the most effective for protecting flavors. Production of off-flavors is a common problem of conventional oxygen scavenging sachets and films. Therefore, eliminating or reducing these potential off-flavors is a major concern for developing new oxygen scavenger. Cyclodextrin has other advantages, such as its thermal and chemical stability. The new $\mathrm{O}_{2}$ scavenger based on ascorbyl palmitate- $\beta$-cyclodextrin inclusion complex was 
able to reduce oxygen content under 4 and $23{ }^{\circ} \mathrm{C}$ more than iron powder based sachet. In addition, the effect of thermal processing on oxygen scavenging capability was also investigated, and the $\mathrm{O}_{2}$ scavenger developed maintained good oxygen scavenging capability after thermal processing. The results indicated that ascorbyl palmitate- $\beta-$ cyclodextrin inclusion complex is an effective $\mathrm{O}_{2}$ scavenger.

Gibis and Rieblinger (2011) incorporate the oxygen scavenger into the packaging material aiming to achieve better quality preservation and longer shelf-life of the chilled food. First investigations concentrated on defining the influence of temperature to the oxygen consumption of an oxygen scavenger film. Reducing the temperature from $23{ }^{\circ} \mathrm{C}$ to $5{ }^{\circ} \mathrm{C}$ caused a decrease (factor 3.0) in the oxygen consumption rate of the oxygen scavenger multilayer film PE /AL(SP2400; PE) within the first four days (RH $100 \% ; 0.5 \%$ initial headspace-oxygen). Moreover the influence of using a polymer with a higher oxygen permeation rate than PP (commonly used) to the oxygen consumption of the scavenger film was investigated. Thus the masterbatch SP2500 was mixed with EVA that shows higher oxygen permeability than PP (by factor 2.3). Consequently the oxygen scavenger multilayer film PE/AL(SP2500; EVA) showed a faster oxygen consumption than the film PE/AL(SP2500; $\mathrm{PP}$ ) (by factor 2.3). Finally the oxygen concentration in measuring cells with scavenger film $\mathrm{PE} / \mathrm{AL}(\mathrm{SP} 2500 ; \mathrm{EVA})$ and with sausage were compared at $5{ }^{\circ} \mathrm{C}$ (initial oxygen concentration in headspace: $0.5 \%$ ). The combination (calculated) with oxygen scavenger film showed a faster oxygen decrease in the headspace of the measuring cell than the sausage alone. This leads to the assumption of a certain protection of the sausage against oxygen deterioration. Better protection of the sausages might be achieved by storing the food sample in combination with the scavenger film in darkness for the first few days. This would allow the scavenger to absorb the oxygen much faster than the sausage because the fast photooxidation processes in the food do not appear without light-exposure.

Absorption kinetics of two commercial $\mathrm{O}_{2}$ and $\mathrm{CO}_{2}$ scavengers $\left(\mathrm{ATCO}^{\circledR} \mathrm{LH}-100\right.$ and $\mathrm{ATCO}^{\circledR}$ CO-450, respectively) commonly used in active modified atmosphere packaging (MAP), were studied. Individual scavenger sachets were placed in polyvinylidene chloride pouches filled with air or modified atmosphere at $0 \%$ or $100 \%$ relative humidity and at 5, 20 and 35 ${ }^{\circ} \mathrm{C}$. The headspace gas composition was measured as a function of time. Absorption kinetics were described by a first-order reaction with an Arrhenius type behaviour. The absorption capacity, absorption rate constant, energy of activation, Arrhenius constant and variation of all these parameters were evaluated This study illustrated the importance to take into account the temperature effect and the variation of the scavenger absorption kinetics to understand gas kinetics inside pouches, as well as to predict the product quality in modified atmosphere packaging (Charles et al., 2006).

Rodrigues et al. (2012) evaluated the antioxidant capacities of gum arabic and maltodextrin microcapsules containing antioxidant molecules (trolox, $\alpha$-tocopherol, $\beta$-carotene, apo- $8^{\prime}$ carotenal and apo-12'-carotenal) against reactive oxygen and nitrogen species. The scavenging capacities were influenced by the wall material, the reactive species, namely $\mathrm{ROO} \bullet, \mathrm{H}_{2} \mathrm{O} 2, \mathrm{HO} \bullet, \mathrm{HOCl}$ and $\mathrm{ONOO}^{-}$, and the antioxidant molecule. In general, a more pronounced enhancement of the antioxidant capacity due to incorporation of antioxidant 
molecules was observed in gum arabic microcapsules. The empty microcapsules showed capacity to scavenge reactive oxygen species (ROS) and reactive nitrogen species (RNS), being gum arabic a more potent antioxidant than maltodextrin. Apo-8'-carotenal incorporation promoted the highest increase in the scavenging capacities among the evaluated antioxidants, varying from $50 \%$ to $132 \%$ and from $39 \%$ to $85 \%$ for gum arabic and maltodextrin microcapsules, respectively, suggesting that this carotenoid presented the best balance between the molecule localization inside the microcapsules and the reactivity against the specific reactive species. These results contribute to the development of multi-functional microcapsules that are able to scavenge a broad range of reactive species of biological relevance, serving as a dietary supplement or as antioxidants for food products, and can also be used as colourants in hydrophilic matrices, such as foods and drugs, without raising the fat content.

Zeolites (mostly faujasites) with adsorbed terpenes ((R)-(+)-limonene or D-pinene) or phenol derivatives (thymol, resorcin, pyrocatechol) have been applied as effective oxygen scavengers of oxygen in packing bags. Their efficiency depends on type of zeolite and on cation modification. Na- and $\mathrm{Cu}$-forms of zeolites $\mathrm{X}$ and $\mathrm{Y}$ accelerate the oxidation of terpenes greatly, whereas the $\mathrm{H}$-forms retard the reaction with oxygen. The reactivity of phenol derivatives with oxygen is also affected by the zeolite support markedly. Although the reactivity of phenols does not increase after adsorption on zeolites, the oxidation products remain adsorbed and do not affect the packing system (Frydrych et al., 2007).

An oxygen scavenging system (OSS), composed of oxygen scavenging nanoparticles $\alpha$ tocopherol and iron chloride (II), was incorporated into warm-water fish gelatin film and their oxygenvscavenging capability was investigated. The initial oxygen content (\%) in the cup headspace, $20.90 \%$, was decreased to $4.56 \%$ after 50 days of storage. The oxygen scavenging fish gelatin (OSFG) film had good oxygen scavenging capacity,1969.08 cc O2/ $2 / 2 / \mathrm{mil}$, and moisture was used as the activator to trigger the oxygen scavenging reaction (Byun et al., 2012).

The researches briefly presented above show that there is an increasing interest in the oxygen scavengers field, and that the role of packaging in food preservation is more active, contributing for extending food shelf-life.

\section{Author details}

Renato Souza Cruz,

Technology Department, State University of de Feira de Santana, Feira de Santana, BA, Brazil

Geany Peruch Camilloto and Ana Clarissa dos Santos Pires*

Food Tecnhology Department, Federal University of Viçosa, Viçosa, MG, Brazil

\section{References}

Abe Y, Kondoh Y (1989) CA/MA vacuum packaging of foods. In: Oxygen absorbers. Trumbull, Westport, CT, pp. 149-158.

\footnotetext{
${ }^{*}$ Corresponding Author
} 
Abe Y (1994) Active packaging with oxygen absorbers. In Ahvenainen R, Nattila-Sandholm T, Ohlsson T. Minimal processing of foods. VTT symposium 142, Espoo, pp. 209-233.

Ackerley DF, Barski RFJr, Cashhill PJ, Chen SY, Johnson DC, Nyderek WM, Rotter GE (1998) Zero Oxygen Permeation Plastic Bottle for Beer and Other Applications. WO Patent 9,812,127.

Ahvenainen R, Hurme E (1997) Active and smart packaging for meeting consumer demands for quality and safety. Food addit contam. 14:753-763.

Akkapeddi MK, Tsai M (2002) Ultra High Oxygen Barrier Films and Articles Made Therefrom. US Patent 6,479,160.

Al-Malaika S, Goodwin C, Issenhuth S, Burdick D (1999) The antioxidant role of $\alpha$ tocopherol in polymers II. Melt stabilizing effect in polypropylene. Polym Degrad Stabil. 64: 145-156.

Altieri C, Sinigaglia M, Corbo MR, Buonocore GG, Falcone P, Del Nobile MA (2004) Use of entrapped microorganisms as biological oxygen scavengers in food packaging applications. LWT 37: 9-15.

Anon. (2004) US invasion - it dominates the US, but Multisorb is pushing its oxygen scavengers in Europe. Active \& intelligent pack news. 2: 5.

Anon. (2005) Up and active - Pira's latest market report plots a healthy future for active packaging. Active \& intelligent pack news. 3: 5.

Anthierens T, Ragaert P, Verbrugghe S, Ouchchen A, De Geest BG, Noseda B, Mertens J, Beladjal L, De Cuyper D, Dierickx W, Du Prez F, Devlieghere F (2011) Use of endospore-forming bacteria as an active oxygen scavenger in plastic packaging materials. Innov. Food Sci. Emerg. Tech. 12:594-599.

ATCO $^{\circledR}$ Technical Information (2002) ATCO ${ }^{\circledR}$ oxygen absorbers, Standa Industrie, France.

Bagchi K, Puri S (1998) Free radicals and antioxidants in health and disease. East Mediterr Health J. 4: 350-360.

Barski RFJr, Richardson JA, Cahill PJ, Rotter GE, Wass RV, Nyderek WM, Smyser GL (2002) Active Oxygen Scavenger Compositions and Their Use in Packaging Articles. US Patent $6,346,308$.

Bioka Technical Information (1999) Bioka oxygen absorber, Bioka Oy, Finland.

Brody AL, Budny JA (1995) Enzymes as active packaging agents. In: Rooney ML (Ed) Active Food Packaging. London, Blackie Academic Professional. pp.174-192.

Brody AL, Strupinsky ER, Kline LR (2001a) Oxygen scavenger systems. In: Active Packaging for Food Applications. Pennsylvania, USA, Technomic Publishing Company.

Brody AL, Strupinsky ER, Kline, LR (2001b) Active packaging for food applications. Lancaster: Technomic Publishing Co., Inc. 218 p.

Butler, B.L. (2002). Cryovac ${ }^{\circledR}$ OS2000TM Polymeric oxygen scavenging systems. Presented at Worldpak 2002. http://www.sealedair.com/library/articles/article-os2000.html

Byun Y, Bae HJ, Whiteside S (2012) Active warm-water fish gelatin film containing oxygen scavenging system. Food Hydrocol 27: 250-255.

Byun Y, Darby D, Cooksey K, Dawson P, Whiteside S (2011) Development of oxygen scavenging system containing a natural free radical scavenger and a transition metal. Food Chem. 124: 615-619.

Byun Y, Kim Y, Whiteside S (2010) Characterization of an antioxidant polylactic acid (PLA) film prepared with $\alpha$-tocopherol, BHT and polyethylene glycol using film cast extruder. J Food Eng. 100: 239-244. 
Byun Y, Whiteside S (2012) Ascorbyl palmitate- $\beta$-cyclodextrin inclusion complex as an oxygen scavenging microparticle. Carbohydrate Pol. 87:2114-2119.

Cahill PJ, Chen SY (2000) Oxygen Scavenging Condensation Copolymers for Bottles and Packaging Articles. US Patent 6,083,585.

Cecchi T, Passamonti P, Cecchi P. (2010) Study of the quality of extra virgin olive oil stored in PET bottles with or without an oxygen scavenger. Food Chem. 120: 730-735.

Charles F, Sanchez J, Gontard N (2006) Absorption kinetics of oxygen and carbon dioxide scavengers as part of active modified atmosphere packaging. J. Food Eng. 72: 1-7.

Choe E, Min DB (2006) Chemistry and reactions of reactive oxygen species in foods. Crit Rev Food Sci Nutr. 46: 1-22.

Cruz RS, Soares NFF, Andrade NJ (2005) Absorvedores de oxigênio na conservação de alimentos: Uma revisão. Rev Ceres. 52: 191-206.

Cruz RS, Soares NFF, Andrade NJ (2006) Evaluation of oxygen absorber on antimicrobial preservation of lasagna -type fresh pasta under vacuum packed. Cienc. Agrotec. 30: 1135-1138.

Cruz RS, Soares NFF, Andrade NJ (2007) Efficiency of oxygen - absorbing sachets in different relative humidities and temperatures. Cienc. Agrotec. 31: 1800-1804.

Damaj Z, Naveau A, Dupont L, Hénon E, Rogez G, Guillon E (2009) Co(II)(L-proline) ${ }_{2}\left(\mathrm{H}_{2} \mathrm{O}\right)_{2}$ solid complex: Characterization, magnetic properties, and DFT computations. Preliminary studies of its use as oxygen scavenger in packaging films. Inorg. Chem. Commun. 12: 17-20.

Day BPF (1998) Active packaging of foods. CCFRA New technologies bulletin. 17: 1-23.

Day BPF (2003) Active packaging. In: Coles R, McDowell D, Kirwan M. (Eds) Food Packaging Technologies. Boca Raton, FL, USA: CRC Press, pp. 282-302.

Doran PM, Bailey JE (1986) Effects of immobilization on growth, fermentation properties, and macromolecular composition of Saccharomyces cerevisiae attached to gelatin. Biot Bioeng. 28: 73-87.

Edens L, Farin F, Ligtvoet AF, Van Der Platt JB (1992) Dry yeast immobilized in wax or paraffin for scavenging oxygen. US Patent 5106633.

Floros JD, Dock LL, Han JH (1997) Active packaging technologies and applications. Food Cosmet Drug Packag. 20:10-17.

Frydrycha E, Foltynowicz Z, Kowalakb S, Janiszewskab E (2007) Oxygen scavengers for packing system based on zeolite adsorbed organic compounds. In: Xu R, Gao Z, Chen J, Yan W (Eds) Zeolites to Porous MOF Materials - the $40^{\text {th }}$ Anniversary of International Zeolite Conference. Elsevier B.V., pp: 1597-1604.

Gibis D, Rieblinger K (2011) Oxygen scavenging films for food application. Proc Food Sci 1:229-234.

Goodrich JL, Schmidt RP, Jerdee GD, Ching TY, Leonard JP, Rodgers BD (2003) Oxygen Scavenging Packaging. US Patent 6569506.

Gosmann B, Rehem HJ (1986) Oxygen uptake of microrganisms entrapped in Ca-alginate. Appl Microbiol Biot. 23: 163-167.

Gosmann B, Rehem HJ (1988) Influence of growth behaviour and physiology of alginateentrapped microorganisms on the oxygen consumption. Appl Microbiol Biot. 29: 554-559.

Graff E. (1994) Oxygen removal. US patent 5284871

Graff G (1998) O2 scavengers give "smart" packaging a new lease on shelflife. Mod Plast. 75: 69-72. 
Hamilton RJ, Kalu C, Prisk E, Padley FB, Pierce H (1997) Chemistry of freeradicals in lipids. Food Chem. 60: 193-199.

Ho YC, Yam KL, Young SS, Zambetti PF (1994) Comparison of vitamin E, IRGANOX 1010 and BHT as antioxidants on release of off-flavors from HDPE bottles. J. Plast Film Sheet. 10:194-212.

Jo C, Ahn DU, Byun MW (2002) Irradiation-induced oxidative changes and production of volatile compounds in sausages prepared with vitamin E-enriched commercial soybean oil. Food Chem. 76: 299-305.

Kulzick MA, Cahill PJ, Barnes TJ, Bauer CW, Johnson DC, Lynch T-Y, Rotter GE, Nyderek WM (2000) Improved Active Oxygen Scavenger Packaging. WO Patent 0037321.

Kruijf N, van Beest M, Rijk R, Sipiläinen-Malm T, Paseiro Losada P, De Meulenaer B (2002) Active and intelligent packaging: applications and regulatory aspects. Food Addit Contam. 19: 144-162.

Labuza TP (1897) Oxygen absorber sachets. Food Res. 32: 276-277.

Labuza TP, Breene WM (1989) Applications of active packaging for improvement of shelf-life and nutritional quality of fresh and extended shelf-life foods. J Food Process Pres. 13: 1-69.

Lacoste A, Schaich KM, Zumbrunnen D, Yam KL (2005) Advancing controlled release packaging through smart blending. Packag Tech Sci. 18: 77-87.

Laermer SF, Young SS, Zambetti PF (1996) Could your packaging use a dose of vitamin E? Converting Magazine. 80-82.

Miltz J, Hoojjat P, Han J, Giacin JR, Harte BR, Gray IJ (1989) Loss of antioxidants from high density polyethylene-its effect on oatmeal cereal oxidation. In: Food and Packaging Interactions. Washington D.C. ACS Symposium 365.

Mize JAJr, Stockley HWIII, Logan RH, Miranda NR (1996) Peelable Package with Oxygen Scavenging Layer. EP Patent 0698563.

Mohan CO, Ravishankar CN, Srinivasa Gopal TK, Ashok Kumar K, Lalitha KV (2009) Biogenic amines formation in seer fish (Scomberomorus commerson) steaks packed with $\mathrm{O}_{2}$ scavenger during chilled storage. Food Res. Int. 42: 411-416.

Morgan CR, Speer DV, Roberts WP (1992) Methods and Compositions for Oxygen Scavenging. EP Patent 0520257 A3 B1.

Nakamura H, Hoshino J (1983) Techniques for the preservation of food by employment of an oxygen absorber. Mitsubishi Gas Chemical Co., Tokyo, Ageless ${ }^{\circledR}$ Division, 1-45.

Nezat JW (1985) Composition for absorbing oxygen and carrier thereof. US Patent 4510162.

Nielsen T (1997) Active packaging-a literature review, The Swedish Institute for Food and Biotechnology, 631, Sweden.

Ohlsson T, Bengtsson N (2002) Active and intelligent packaging: oxygen absorbing packaging materials. In: Minimal Processing Technologies in the Industry. Cambridge, Woodhead Publishing Limited and CRC Press LLC.

Ozdemir M, Floros JD (2004) Active Food Packaging Technologies. Crit Rev Food Sci Nut. 44:185-193.

Roberts WP, Vanputte AW, Speer DV, Morgan CR (1996) Multilayer Structure for A Package for Scavenging Oxygen. US Patent 5350622.

Rodrigues E, Mariutti LBR, Faria AF, Mercadante AZ (2012) Microcapsules containing antioxidant molecules as scavengers of reactive oxygen and nitrogen species. Food Chem (article in press). 
Rooney ML (1995) Active packaging in polymer films. In: Active Food Packaging. London, Blackie Academic Professional.

Rooney ML (2005) Introduction to active food packaging technologies. In: Han JH (Ed) Innovations in Food Packaging. London, UK: Elsevier Ltd., pp. 63-69.

Roussel (1999) Les emballages absorbeurs d'oxygène. In: Gontard N (Ed) Les emballages actifs. Paris, Tec and Doc, pp. 31-37.

Santiago-Silva P, Soares NFF, Nóbrega JE, Júnior MAW, Barbosa KBF, Volp ACP, Zerdas ERMA, Würlitzer NJ (2009) Antimicrobial efficiency of film incorporated with pediocin (ALTA $^{\circledR} 2351$ ) on preservation of sliced ham. Food Control 20: 85-89.

Shorter AJ (1982) Evaluation of rapid methods for scavenging oxygen in flexible pouches. LWT. 5: 380-381.

Siro I, Fenyvesi E, Szente L, Meulenaer BD, Devlieghere F, Orgovanyi J, Sényi J, Barta, J (2006) Release of alpha-tocopherol from antioxidative low density polyethylene film into fatty food simulant: influence of complexation in beta-cyclodextrin. Food Addit Contam 23: 845-853.

Smith JP (1996) Improving shelf life of packaged baked goods by oxygen absorbents. AIB research department technical bulletin. 18: 2-7.

Smirnoff N (2005) Ascorbate, tocopherol and carotenoids: metabolism, pathway engineering and functions. In: Antioxidants and reactive oxygen species in plants. New York: Blackwell Publishing, pp. 53-86.

Speer DV, Cotterman RL, Kennedy TD (2002) Process for Pasteurizing an Oxygen Sensitive Product and Triggering an Oxygen Scavenger and the Resulting Package. US Patent 2002142168.

Speer DV, Roberts WP (1994) Oxygen Scavenging Compositions for Low Temperature Use. US Patent 5310497.

Suppakul P, Miltz J, Sonneveld K, Bigger SW (2003) Active packaging technologies with an emphasis on antimicrobial packaging and its applications. J Food Sci. 68: 408-420.

Tramper J, Luyben KCAM, van der Tweel WJJ (1983) Kinetic aspects of glucose oxydation by Gluconobacter oxydans cells immobilized in Ca-alginate. Eur J Appl Microbiol. 17: 13-18

van Ruth SM, Shaker ES, Morrissey PA (2001) Influence of methanolic extracts of soybean seeds and soybean oil on lipid oxidation in linseed oil. Food Chem. 75:177-184.

Vermeiren L, Devlieghere F, van Beest M, de Kruijf N, Debevere J (1999) Developments in the active packaging of foods. Trends Food Sci. Tech. 10: 77-86.

Vermeiren L, Heirlings L, Devlieghere F, Debevere J (2003) Oxygen, ethylene and other scavengers. In: Ahvenainen R (Ed.) Novel food packaging techniques. Boca Raton, USA, CRC Press.

Wessling C (2000) Antioxidant-Impregnated Polymers Antioxidant Ability and Interactions with Food. Ph.d Thesis Cornell University Ithaca NY USA.

Wessling C, Nielsen T, Leufven A (2000) The influence of $\alpha$-tocopherol concentration on the stability of linoleic acid and the properties of low density polyethylene. Packag Tech Sci. 13: 19-28.

Wessling C, Nielsen T, Leufven A, Jagerstad M (1998) Mobility of tocopherol and BHT in LDPE in contact with fatty food simulants. Food Addit Contam. 15: 709-715.

Zerdin K, Rooney ML, Vermuë J (2003) The vitamin C content of orange juice packed in an oxygen scavenger material. Food Chem. 82: 387-395. 